\title{
Commentary CYP17 and breast cancer: no overall effect, but what about interactions?
}

\author{
Julian Little ${ }^{1}$ and Jacques Simard ${ }^{2}$
}

\begin{abstract}
${ }^{1}$ Canada Research Chair in Human Genome Epidemiology, Department of Epidemiology and Community Medicine, University of Ottawa, Ontario, Canada

${ }^{2}$ Canada Research Chair in Oncogenetics, Cancer Genomics Laboratory, Oncology and Molecular Endocrinology Research Center, CHUQ Research Center and Laval University, Quebec, Canada
\end{abstract}

Corresponding author: Julian Little, jlittle@uottawa.ca

Published: 20 September 2005

This article is online at http://breast-cancer-research.com/content/7/6/238

(c) 2005 BioMed Central Ltd

Breast Cancer Research 2005, 7:238-242 (DOI 10.1186/bcr1320)

See related research by Verla-Tebit et al. [http://breast-cancer-research.com/content/7/4/R455], Chang et al. [http://breast-cancer-research.com/ content/7/4/R513] and Einarsdottir et al. [http://breast-cancer-research.com/content/7/6/R890]

\begin{abstract}
Three large studies published in recent issues of Breast Cancer Research reported no overall evidence of an association between the CYP17 5'-untranslated region MspA1 polymorphism and breast cancer. The present commentary briefly highlights a few important observations and discusses some additional approaches to further assessment of associations between CYP17 common variants and breast cancer risk. In particular, the evolution of evidence on breast cancer and the CYP17 MspA1 variant suggests that determination of possible interactions between gene variants postulated to influence risk and nongenetic risk factors would be more efficiently accomplished by pooled analyses, ideally involving all studies of breast cancer, than by attempting to synthesize published information. Furthermore, such analyses would also be relevant to investigation of potential gene-gene interactions between CYP17 and other common variants in genes encoding enzymes that are involved in the synthesis and inactivation of sex steroid hormones, preferably using optimal sets of single nucleotide polymorphisms.
\end{abstract}

\section{Introduction}

The importance of hormonal factors in the aetiology of breast cancer and its response to treatment are firmly established, and so it would be expected that factors that modulate hormonal exposure will modify risk. However, in three recent large studies of breast cancer [1-3] there was no overall evidence of association with the CYP17 5'-untranslated region MspA1 polymorphism, which is in contrast to some earlier work. This polymorphism has been of interest to breast cancer investigators because the enzyme encoded by the gene, namely cytochrome P450c17, functions at key branch points in steroid hormone biosynthesis. Human P450c17 predominantly catalyzes the formation of the precursor dehydroepiandrosterone (DHEA), which is converted into androgens and/or oestrogens in the ovary and in peripheral intracrine tissues (e.g. breast, bone, skin and adipose tissue) through tissue-specific enzymatic pathways [4-6]. Current evidence does not support the involvement of this polymorphism in CYP17 transcriptional regulation [7-9]. Whereas the CYP17 MspA1 genotype has been found to be associated with circulating oestrogen levels in premenopausal women in some studies [10], in recent large population-based studies [11] no association with oestradiol concentrations in either premenopausal or postmenopausal women was observed, and in postmenopausal women there were no clear associations with circulating levels of oestrogens or androgens [12,13]. However, because of the limitations of functional assays, there is a strong argument that the primary emphasis should be on epidemiological evidence for its association with breast cancer risk [14].

\section{CYP17 genotype and breast cancer risk}

The effects of genetic factors in aetiology might be expected to become stronger with earlier age at onset. The results of previous studies of the association between the MspA1 variant and breast cancer with earlier age of onset were inconsistent $[7,15-26]$. This may in part be due to differences in study methods. For example, some studies were not population based $[16,18,19,22,26]$, which renders them susceptible to the effects of selection bias. In one [17] a substantial proportion of cases was prevalent, which would bias the results if CYP17 genotype influenced survival. The studies differed markedly in size, and so they varied in statistical power to detect an effect. 
The three most recent studies [1-3] were population based, and only cases with newly incident disease were included. One included women clearly defined as premenopausal (aged 50 years and under who still had menstrual cycles or who reported natural amenorrhoea for less than 6 months before diagnosis/interview) resident in two regions of southern Germany [1]. Data on 527 cases with in situ or invasive disease diagnosed during the period 1992-1995 were compared with data on 904 control individuals randomly selected from population registers and matched with cases in terms of age and study region. These represent about $80 \%$ of individuals on whom interview data had been obtained, and the losses represent the strict application of criteria for selecting women who were premenopausal and genotyping failure. There were no differences between the cases and controls for whom genotype data were available and the total cases and controls interviewed in terms of the distribution of sociodemographic factors or putative risk factors for breast cancer.

Compared with homozygotes for the A1 allele, the ageadjusted odds ratio (OR) for breast cancer in heterozygotes was 1.02 (95\% confidence interval $[\mathrm{Cl}] 0.80-1.31)$ and the OR in homozygotes for the A2 allele was $1.18(95 \% \mathrm{Cl}$ 0.87-1.61) [1]. These estimates were little changed with further adjustment for breast cancer risk factors. Possible effect modification was examined for age at menarche, oral contraceptive use, parity, age at first full-term pregnancy, and breastfeeding status. Such a modification was apparent only for parity, with increased risk among nulliparous women homozygous for the A2 allele.

The second study [2] included women aged under 60 years diagnosed in Melbourne or Sydney (Australia) during the period 1992-1999, with stratified sampling of cases so that half were diagnosed at age under 40 years. A total of 2303 (1208 under 40 years old; 1095 aged $40-59$ years) cases with invasive breast cancer were identified from cancer registries [27]. Interviews were completed for 1578 (69\%). After excluding women who were not white, cases aged under 40 years in whom BRCA1 and BRCA2 mutations were found $(n=41)$, and genotyping failures, 1284 cases were included in the analysis [2]. A total of 1531 controls were selected from electoral rolls by proportional random sampling, based on the expected age distribution of cases, of whom 1021 (67\%) were interviewed [27]; 679 were included in the analysis. There is overlap with an earlier report [15] on 369 cases diagnosed under 40 years during the period 1992-1995 and 284 controls. The analysis was stratified by menopausal status.

In premenopausal women (1043 cases, 529 controls), compared with A1 homozygotes, the OR for breast cancer in heterozygotes was $0.88(95 \% \mathrm{Cl} 0.70-1.11)$ and in $\mathrm{A} 2$ homozygotes the OR was 1.09 (95\% Cl 0.79-1.51) [2]. As in the German study [1], adjustment for putative risk factors had little effect on these estimates. Thus, the increased risk in A2 homozygotes that was apparent in women aged under 40 years in a report on a subset of these data [15] was no longer detectable. In postmenopausal women (241 cases, 150 controls), the OR for heterozygotes was 1.09 (95\% Cl $0.70-1.70)$ and for A2 homozygotes the OR was $1.23(95 \%$ $\mathrm{Cl}$ 0.66-2.31). In view of the finding in the earlier study that the increased risk for A2 homozygotes appeared to be confined to women with a family history of breast cancer in a first-degree or second-degree relative [15], the overall analysis was stratified by family history, defined as breast cancer in a first-degree relative [2]. Among women with such a family history, the OR associated with homozygosity for the A2 genotype was 2.5 ; this was not a statistically significant finding. For other possible effect modifications, the authors defined risk categories as in the study conducted by Ambrosone and coworkers [20], which they considered to be the most comprehensive previous assessment of effect modification. Possible effect modification was examined for age at menarche, oral contraceptive use, age at first birth, use of hormone replacement therapy and age at menopause. No evidence of effect modification was found for premenopausal breast cancer. For postmenopausal women there was a suggestion that the increased risk for breast cancer associated with later age at menopause was confined to women homozygous for the A1 allele.

The third study [3] was restricted to postmenopausal women resident in Sweden in the period 1993-1995. Long-term users of menopausal hormones and women with diabetes mellitus were over-sampled. Comparison was made between 1544 cases of invasive breast cancer (73\% of potentially eligible cases) identified through cancer registers, and 1502 controls (61\% of those potentially eligible) selected from the Swedish Total Population Registry. Compared with A1 homozygotes, the OR for breast cancer in A2 homozygotes was $1.0(95 \% \mathrm{Cl} \mathrm{0.8-1.3)}$ and that for heterozygotes was also unity. This lack of association is consistent with most previous studies in which results specific to postmenopausal women were presented [21-26,28], although in studies in Indian [27] and Japanese [19] women the A2A2 genotype was associated with increased risk. This lack of association was also observed when ductal and lobular tumours were analyzed separately. Possible effect modification was examined for menopausal hormone use, age at menarche, age at menopause, age at first birth, parity, and body mass index. Effect modification was apparent only for age at menarche, with A2 homozygotes having an increased risk associated with an early age at menarche and age at menopause, and with A2 carriers having a reduced risk associated with an early age at menopause. Unlike in other studies [29], age at menarche was not associated with overall breast cancer risk in this study.

In all three studies [1-3] there was more than $80 \%$ power to detect an OR of 1.5 or more at the 0.05 level of statistical 
significance. As noted in the Australian study [2], detection of departure from multiplicative joint effects requires at least four times the number of subjects than would a study aimed only at detecting the main effects of genotype and another risk factor [30]. Therefore, the lack of consistency between the findings of the Australian study [2] and the much smaller study (96 premenopausal cases and 86 controls; 111 postmenopausal cases and 102 controls) conducted by Ambrosone and coworkers [20] may reflect the play of chance. There is consistency between the German [1] and Australian [2] studies of premenopausal women in the lack of evidence of a differential effect of CYP17 genotype on risk associated with age at menarche, age at first birth, or use of oral contraceptives. The Swedish study [3] of postmenopausal women detected an interaction with age at menarche, which was interpreted as a chance finding. In contrast to the German study [1], neither the Swedish [3] nor Australian [2] studies showed an increased risk associated with presence of the A2 allele in nulliparous premenopausal women (OR based on crude analysis of data presented in Table 3 in reference [2], assuming all parous women had age at first birth recorded, heterozygotes and A2 homozygotes combined: $0.94,95 \% \mathrm{Cl} 0.61-1.46)$. Crude analysis of the German data [1] suggests that homozygosity for the A2 variant is inversely associated (OR $0.32,95 \% \mathrm{Cl} 0.10-1.04$ ) with risk for premenopausal breast cancer in women with a family history of the disease in first-degree relatives, which is in contrast to the Australian study [2].

In the German [1] and Swedish [3] studies there was no association between CYP17 genotype and stage of breast cancer. This is compatible with most [7,17,21,25,31-33] but not all $[16,24,34]$ previous studies, in which a variety of definitions of extent of disease were used.

One previous study [23] suggested that a high intake of lignans - plant compounds that are metabolized in the gut to produce the phyto-oestrogens enterolactone and enterodiol is associated with a more marked reduction in OR for breast cancer in women who have an $A 2$ allele than in $A 1$ homozygotes. A concern is that this joint effect has been investigated in other studies but not reported. It is noteworthy that associations between intake of lignans and breast cancer was reported in a subset of participants in the German study [35].

\section{Conclusion}

In the analyses of breast cancer in younger women, possible interactions between CYP17 genotype and other gene variants affecting the tissue-specific synthesis and metabolism of steroid hormones do not appear to have been investigated. The metabolism of any exposure is likely to depend on the balance between the relative activities of all of the enzymes in the metabolic pathway [36]. This concept is of particular importance bearing in mind the role played by androgens as well as oestrogens, which exert opposite effects in breast cancer development [5]. In some studies of breast cancer in general (i.e. not specifically in premenopausal women), suggestions of an interaction with the $17 \beta$-hydroxysteroid dehydrogenase type $1[28,37]$ and with CYP1A1 and catechol-O-methyltransferase [26] variants were observed. Pooled analyses would facilitate the investigation of gene-gene interactions.

It should also be kept in mind that the determination of the impact of genetic variant(s) on tissue-specific intracellular sex steroid concentrations has inherent limitations, because these levels do not correlate with measurements of circulating sex steroid levels. Indeed, the serum testosterone and oestradiol levels reflect predominantly the contribution of direct sex steroid secretion by the ovaries and/or adrenals [5]. A better approach to estimating DHEA conversion into active androgens and oestrogens would be to measure circulating conjugated metabolites, such as glucuronidated metabolites [38].

There has been considerable concern about the potential impact of publication bias on the body of knowledge on gene-disease associations [39-41]. The potential for selective publication of results can only increase as a result of the application of a combination of a tremendous expansion in genotyping potential and exploratory statistical analyses in studies with limited sample sizes [42-44]. This problem is compounded for gene-environment and gene-gene interactions because, in addition to the larger number of potential comparisons implicit in the concept of multiple interacting variables, authors face the problem that large tables of geneenvironment interaction estimates are very cumbersome and difficult to assemble in publishable format [45]. This inevitably increases the potential for publication bias.

Therefore, the publication of the null overall findings on CYP17 5'-untranslated region MspA1 genotype and breast cancer, and of the effect modifications investigated $[1,2]$ is particularly welcome. Is there a need for further studies of this polymorphism and breast cancer? The accrued evidence does not indicate any substantial overall effect in white populations, but it is insufficient to exclude an effect in other populations. For the latter, integration of evidence across studies will most efficiently be accomplished using systematic review and pooled analysis methods, such as have been applied in human genome epidemiology reviews [46]. Possible interaction with family history and with nongenetic risk factors has been observed in some studies but has not been replicated. Review of the studies on CYP17 illustrates the difficulties of synthesizing evidence on such interactions, notably differences in definition and categorization of variables and in methods of analysis. Pooled analysis, sometimes described as meta-analysis of individual patient data, offers many advantages over the meta-analysis of the results of studies, including consistent determination of 
subgroup effects, standardization of definitions of cases and variables, and better control of confounding $[47,48]$. This approach will be facilitated by the development of networks of investigators researching gene-disease associations [49].

Is there a need for further studies of genetic variation in CYP17 and breast cancer? In single studies, no association has been reported with a G-A transition in the promoter region in Japan [19] or with the c198t or g255t single nucleotide polymorphisms (SNPs) in England [13]. The two SNPs in the latter study, together with the MspA1 variant ( $\mathrm{t} 34 \mathrm{c})$, tag the three common haplotypes in the coding region [50]. Although the haplotype tagging SNP approach may prove a valuable direction for gene disease-association studies, there is considerable debate about the optimal strategies for selecting SNPs [51-53]. In theory, additional genotyping of samples from studies already completed would be an efficient way to confirm the presence or absence of effect, with synthesis of the evidence across studies.

\section{Competing interests}

The author(s) declare that they have no competing interests.

\section{References}

1. Verla-Tebit E, Wang-Gohrke S, Chang-Claude J: CYP17 5'-UTR MspA1 polymorphism and the risk of premenopausal breast cancer in a German population-based case-control study. Breast Cancer Res 2005, 7:R455-R464.

2. Chang JH, Gertig DM, Chen X, Dite GS, Jenkins MA, Milne RL, Southey MC, McCredie MR, Giles GG, Chenevix-Trench G, et al.: CYP17 genetic polymorphism, breast cancer, and breast cancer risk factors: Australian Breast Cancer Family Study. Breast Cancer Res 2005, 7:R513-R521.

3. Einarsdottir K, Rylander-Rudqvist T, Humphreys K, et al.: CYP17 gene polymorphism in relation to breast cancer risk: a casecontrol study. Breast Cancer Res 2005, 7:R890-R896.

4. Auchus RJ: Overview of dehydroepiandrosterone biosynthesis. Semin Reprod Med 2004, 22:281-288.

5. Labrie F, Luu-The V, Labrie C, Belanger A, Simard J, Lin SX, Pelletier G: Endocrine and intracrine sources of androgens in women: inhibition of breast cancer and other roles of androgens and their precursor dehydroepiandrosterone. Endocr Rev 2003, 24:152-182.

6. Simard J, Ricketts ML, Gingras S, Soucy P, Feltus FA, Melner MH: Molecular biology of the 3beta-hydroxysteroid dehydrogenase/ delta5-delta4 isomerase gene family. Endocr Rev 2005, 26:525582.

7. Nedelcheva Kristensen V, Haraldsen EK, Anderson KB, Lonning $\mathrm{PE}$, Erikstein B, Karesen R, Gabrielsen OS, Borresen-Dale AL: CYP17 and breast cancer risk: the polymorphism in the 5' flanking area of the gene does not influence binding to Sp-1. Cancer Res 1999, 59:2825-2828.

8. Lin CJ, Martens JW, Miller WL: NF-1C, Sp1, and Sp3 are essential for transcription of the human gene for P450c17 (steroid 17alpha-hydroxylase/17,20 lyase) in human adrenal $\mathrm{NCl}-$ H295A cells. Mol Endocrinol 2001, 15:1277-1293.

9. Lin C, Miller WL: The T/C allelic polymorphism at nucleotide +27 of the human CYP17 gene is not associated with altered transcriptional activity [abstract]. The Endocrine Society 83rd Annual Meeting, June 20-23 2001, Denver, Colorado, USA, P2-1:295.

10. Sharp L, Cardy AH, Cotton SC, Little J: CYP17 gene polymorphisms: prevalence and associations with hormone levels and related factors. a HuGE review. Am J Epidemiol 2004, 160:729-740.

11. Travis RC, Churchman M, Edwards SA, Smith G, Verkasalo PK, Wolf $\mathrm{CR}$, Wolf $\mathrm{H}$, Key TJ: No association of polymorphisms in CYP17, CYP19, and HSD17-B1 with plasma estradiol concentrations in 1,090 British women. Cancer Epidemiol Biomarkers Prev 2004, 13:2282-2284.
12. Tworoger SS, Chubak J, Aiello EJ, Ulrich CM, Atkinson C, Potter JD, Yasui Y, Stapleton PL, Lampe JW, Farin FM, et al:: Association of CYP17, CYP19, CYP1B1, and COMT polymorphisms with serum and urinary sex hormone concentrations in postmenopausal women. Cancer Epidemiol Biomarkers Prev 2004, 13:94-101.

13. Dunning AM, Dowsett M, Healey CS, Tee L, Luben RN, Folkerd E, Novik KL, Kelemen L, Ogata S, Pharoah PD, et al.: Polymorphisms associated with circulating sex hormone levels in postmenopausal women. J Natl Cancer Inst 2004, 96:936-945.

14. Pharoah PD, Dunning AM, Ponder BA, Easton DF: The reliable identification of disease-gene associations. Cancer Epidemiol Biomarkers Prev 2005, 14:1362.

15. Spurdle AB, Hopper JL, Dite GS, Chen X, Cui J, McCredie MR, Giles GG, Southey MC, Venter DJ, Easton DF, et al.: CYP17 promoter polymorphism and breast cancer in Australian women under age forty years. J Natl Cancer Inst 2000, 92:1674-1681.

16. Bergman-Jungestrom M, Gentile M, Lundin AC, The South-East Breast Cancer Group, Wingren S: Association between CYP17 gene polymorphism and risk of breast cancer in young women. Int J Cancer 1999, 84:350-353.

17. Dunning AM, Healey CS, Pharoah PD, Foster NA, Lipscombe JM, Redman KL, Easton DF, Day NE, Ponder BA: No association between a polymorphism in the steroid metabolism gene CYP17 and risk of breast cancer. Br J Cancer 1998, 77:20452047.

18. Young IE, Kurian KM, Annink $C$, Kunkler IH, Anderson VA, Cohen $\mathrm{BB}$, Hooper ML, Wyllie AH, Steel CM: A polymorphism in the CYP17 gene is associated with male breast cancer. $\mathrm{Br} J$ Cancer 1999, 81:141-143.

19. Miyoshi Y, Iwao K, Ikeda N, Egawa C, Noguchi S: Genetic polymorphism in CYP17 and breast cancer risk in Japanese women. Eur J Cancer 2000, 36:2375-2379.

20. Ambrosone CB, Moysich KB, Furberg $\mathrm{H}$, Freudenheim JL, Bowman ED, Ahmed S, Graham S, Vena JE, Shields PG: CYP17 genetic polymorphism, breast cancer, and breast cancer risk factors. Breast Cancer Res 2003, 5:R45-R51.

21. Mitrunen K, Jourenkova N, Kataja V, Eskelinen M, Kosma VM, Benhamou S, Vainio H, Uusitupa M, Hirvonen A: Steroid metabolism gene CYP17 polymorphism and the development of breast cancer. Cancer Epidemiol Biomarkers Prev 2000, 9:1343-1348.

22. Hamajima N, Iwata $H$, Obata $Y$, Matsuo K, Mizutani M, Iwase $T$, Miura S, Okuma K, Ohashi K, Tajima K: No association of the 5' promoter region polymorphism of CYP17 with breast cancer risk in Japan. Jpn J Cancer Res 2000, 91:880-885.

23. McCann SE, Moysich KB, Freudenheim JL, Ambrosone CB, Shields PG: The risk of breast cancer associated with dietary lignans differs by CYP17 genotype in women. J Nutr 2002, 132:3036-3041

24. Helzlsouer KJ, Huang HY, Strickland PT, Hoffman S, Alberg AJ, Comstock GW, Bell DA: Association between CYP17 polymorphisms and the development of breast cancer. Cancer Epidemiol Biomarkers Prev 1998, 7:945-949.

25. Haiman CA, Hankinson SE, Spiegelman D, Colditz GA, Willett WC, Speizer FE, Kelsey KT, Hunter DJ: The relationship between a polymorphism in CYP17 with plasma hormone levels and breast cancer. Cancer Res 1999, 59:1015-1020.

26. Huang CS, Chern HD, Chang KJ, Cheng CW, Hsu SM, Shen CY: Breast cancer risk associated with genotype polymorphism of the estrogen-metabolizing genes CYP17, CYP1A1, and COMT: a multigenic study on cancer susceptibility. Cancer Res 1999, 59:4870-4875.

27. Chacko P, Rajan B, Mathew BS, Joseph T, Pillai MR: CYP17 and SULT1A1 gene polymorphisms in Indian breast cancer. Breast Cancer 2004, 11:380-388.

28. Wu AH, Seow A, Arakawa K, Van Den Berg D, Lee HP, Yu MC: HSD17B1 and CYP17 polymorphisms and breast cancer risk among Chinese women in Sinapore. Int J Cancer 2003, 104: 450-457.

29. Henderson BE, Pike MC, Bernstein L, Ross RK: Breast Cancer. In Cancer Epidemiology and Prevention 2nd Edition. Edited by Schottenfeld D, Fraumeni JF Jr. New York: Oxford University Press; 1996:1022-1039.

30. Dite GS, Jenkins MA, Southey MC, Hocking JS, Giles GG, McCredie MR, Venter DJ, Hopper JL: Familial risks, early-onset breast cancer, and BRCA1 and BRCA2 germline mutations. J Natl Cancer Inst 2003, 95:448-457. 
31. Weston A, Pan CF, Bleiweiss IJ, Ksieski HB, Roy N, Maloney N, Wolff MS: CYP17 genotype and breast cancer risk. Cancer Epidemiol Biomarkers Prev 1998, 7:941-944.

32. Kuligina ES, Togo AV, Suspitsin EN, Grigoriev MY, Pozharisskiy $\mathrm{KM}$, Chagunava OL, Berstein LM, Theillet C, Hanson KP, Imyanitov EN: CYP17 polymorphism in the groups of distinct breast cancer susceptibility: comparison of patients with the bilateral disease vs. monolateral breast cancer patients vs. middleaged female controls vs. elderly tumor-free women. Cancer Lett 2000, 156:45-50.

33. Gudmundsdottir K, Thorlacius S, Jonasson JG, Sigfusson BF, Tryggvadottir L, Eyfjord JE: CYP17 promoter polymorphism and breast cancer risk in males and females in relation to BRCA2 status. Br J Cancer 2003, 88:933-936.

34. Feigelson HS, Coetzee GA, Kolonel LN, Ross RK, Henderson BE: A polymorphism in the CYP17 gene increases the risk of breast cancer. Cancer Res 1997, 57:1063-1065.

35. Linseisen J, Piller R, Hermann S, Chang-Claude J, German CaseControl Study: Dietary phytoestrogen intake and premenopausal breast cancer risk in a German case-control study. Int J Cancer 2004, 110:284-290.

36. Wolf CR, Smith G: Chapter 18: cytochrome P450 CYP2D6. In Metabolic Polymorphisms and Susceptibility to Cancer. Edited by Vineis P, Malats N, Lang M, d'Errico A, Caporaso N, Cuzick J, Boffetta P. Lyon, France: IARC Scientific Publications; 1999:209229.

37. Feigelson HS, McKean-Cowdin R, Coetzee GA, Stram DO, Kolonel LN, Henderson BE: Building a multigenic model of breast cancer susceptibility: CYP17 and HSD17B1 are two important candidates. Cancer Res 2001, 61:785-789.

38. Labrie F, Belanger A, Cusan L, Candas B: Physiological changes in dehydroepiandrosterone are not reflected by serum levels of active androgens and estrogens but of their metabolites: intracrinology. J Clin Endocrinol Metab 1997, 82: 2403-2409.

39. loannidis JPA Ntzani EE, Trikalinos TA, Contopoulos-loannidis DG: Replication validity of genetic association studies. Nat Genet 2001, 29:306-309.

40. Hirschhorn JN, Lohmueller K, Byrne E, Hirschhorn K: A comprehesive review of genetic association studies. Genet Med 2002, 4:45-61.

41. Little J, Bradley L, Bray MS, Clyne M, Dorman J, Ellsworth DL, Hanson J, Khoury M, Lau J, O'Brien TR, et al.: Reporting, appraising, and integrating data on genotype prevalence and genedisease associations. Am J Epidemiol 2002, 156:300-310.

42. Wacholder S, Chanock S, Garcia-Closas M, El ghormli L, Rothman N: Assessing the probability that a positive report is false: an approach for molecular epidemiology studies. J Natl Cancer Inst 2004, 96:434-442.

43. Thomas DC, Clayton DG: Betting odds and genetic associations. J Nat/ Cancer Inst 2004, 96:421-423.

44. loannidis JPA, Bernstein J, Boffetta P, Danesh J, Dolan S, Hartge $\mathrm{P}$, Hunter D, Inskip P, Jarvelin M-R, Little J, et al.: A network of investigator networks in human genome epidemiology. $A m \mathrm{~J}$ Epidemiol 2005, 162:302-304.

45. Little J: Reporting and review of human genome epidemiology studies. In Human Genome Epidemiology: a Scientific Foundation for using Genetic Information to Improve Health and Prevent Disease. Edited by Khoury MJ, Little J, Burke W. New York: Oxford University Press; 2004:168-192.

46. Little J, Khoury MJ, Bradley L, Clyne M, Gwinn M, Lin B, Lindegren $\mathrm{ML}$, Yoon $\mathrm{P}$ : The human genome project is complete. How do we develop a handle for the pump? Am J Epidemiol 2003, 157: 667-673.

47. Friedenreich CM: Methods for pooled analyses of epidemiologic studies. Epidemiology 1993, 4:295-302

48. Ioannidis JP, Rosenberg PS, Goedert JJ, O'Brien TR: Commentary: meta-analysis of individual participants' data in genetic epidemiology. Am J Epidemio/ 2002, 156:204-210.

49. loannidis JP, Bernstein J, Boffetta P, Danesh J, Dolan S, Hartge P, Hunter D, Inskip P, Jarvelin MR, Little J, et al.: A network of investigator networks in human genome epidemiology. Am J Epidemiol 2005, 162:302-304.

50. Cargill M, Altshuler D, Ireland J, Sklar P, Ardlie K, Patil N, Shaw N, Lane CR, Lim EP, Kalyanaraman N, et al:: Characterization of single-nucleotide polymorphisms in coding regions of human genes. Nat Genet 1999, 22:231-238.
51. Carlson CS, Eberle MA, Rieder MJ, Yi Q, Kruglyak L, Nickerson $D A$ : Selecting a maximally informative set of single-nucleotide polymorphisms for association analyses using linkage disequilibrium. Am J Hum Genet 2004, 74:106-120.

52. Neale BM, Sham PC: The future of association studies: genebased analysis and replication. Am J Hum Genet 2004, 75: 353-362.

53. Zhang W, Collins A, Morton NE: Does haplotype diversity predict power for association mapping of disease susceptibility? Hum Genet 2004, 115:157-164. 